\title{
Work in progress: Faculty perceptions of project-enhanced learning in early engineering education: Barriers and benefits
}

Robert J. Helfenbein ; M. Razi Nalim ; Manikanada K. Rajagopal

\begin{abstract}
The application of problem-based learning (PBL) to undergraduate engineering education has emerged as an area of research interest over the past few decades, although it does not appear to be the dominant pedagogy for most engineering programs. A related form of active learning is projectenhanced learning (PEL), specifically designed to enhance but not replace traditional teaching methods in engineering science courses. The perceptions of instructors who attempt PEL were examined using extended-term mixed-method approaches, seeking to examine perceived benefits and barriers to PEL as an intervention for improved student learning. Instructors expressed satisfaction with improved student motivation, interaction, and socialization, which may help with student success and retention in engineering. Instructors also expressed concern about losing focus on the challenging analytical course topics, but were able to achieve appropriate balance by designing project tasks to align well with the topics and limiting non-aligned project activity.
\end{abstract}

\section{Keywords}

Problem based learning, Project-enhanced learning, Engineering science, Engineering education

This is the author's manuscript of the article published in final edited form as:

Helfenbein, R. J., Nalim, M. R., \& Rajagopal, M. K. (2012). Work in progress: Faculty perceptions of project-enhanced learning in early engineering education: Barriers and benefits. 2012 Frontiers in Education Conference Proceedings, 1-6. https://doi.org/10.1109/FIE.2012.6462493 


\section{Section I.}

\section{Introduction}

This paper represents the initial findings of the NSF-funded study "Implementation, Dissemination, Barrier Identification and Faculty Training for Project-Enhanced Learning in Gateway Engineering Courses" and highlights faculty perceptions of the use of Project-Enhanced Learning (PEL) strategies specifically in sophomore and junior-level engineering science courses. PEL is defined as an integrated project within a traditional lecture-based course that can be implemented in a gradual and transferable way and across multiple sections and instructors [1]. As many undergraduates perform poorly in early engineering science courses that are primarily lecture-based, attention to pedagogical innovation may present an opportunity for increased retention. Additionally, surveys, and classroom assessments indicate that many students completing these courses did not really understand the fundamentals, even if they could apply the 'formulae'.

The guiding research approach for the project follows the Extended-Term Mixed-Method (ETMM) design [2]. This design includes five inter-related principles: (a) developing a long-term time-line, (b) using theory and data to inform decisions, (c) paying attention to formative and summative components of the study, (d) creating sharply focused causal questions regarding impact of the program, and (e) using a variety of quantitative and qualitative evidence to support claims. Workshop observation, qualitative interviews, and a constant-comparative analysis [3] were utilized in the research design.

The participants in this project have designed and implemented project experiences in three different 'gateway' engineering science courses, based on initial experiences in a course on Thermodynamics. We refer to the first courses in the engineering major as 'gateway' engineering courses, specifically courses in engineering sciences. In Fall 2011, PEL was introduced in two other courses: Probabilistic Methods In Electrical And Computer Engineering, and Dynamics in the mechanical engineering curriculum [4]. One or two major projects based on authentic systems, objects, or activities are designed and assigned to apply key course topics. The goals include increasing student motivation, provide realistic application of abstract concepts, and long-term learning retention. Teamwork, increased communication with Engineering faculty and professionalism were also emphasized. Significant findings include faculty perceptions of both the value of and barriers to implementing a PEL component in gateway engineering courses and an underlying understanding of the need for increased student engagement in the engineering curriculum.

\section{Section II.}

\section{Literature Review}

For most college majors, the first year is the most critical for persistence in college. Tinto [5] observed that almost one-half of students entering two-year colleges and more than one-fourth (28.5\%) of students entering four-year collegiate institutions leave at the end of their first year. However, a significant fraction of students who decide at that point to persist in engineering, nonetheless leave engineering in the middle years of college [6]. Practitioners and scholars seek explanations, whereas college and university administrators desire to manage their student enrollments by reducing such rates of departure. The findings [6] indicate that faculty classroom behaviors in general and active learning in 
particular (of which PEL may be considered a form) may constitute an empirically reliable source of influence on social integration, subsequent institutional commitment, and departure decisions.

A large body of research affirms that active learning enhances student knowledge and understanding of course content [7]-[8][9][10]. Moreover, students who frequently encounter active learning in their courses perceive themselves gaining knowledge and understanding from their course work. As a consequence of this self-efficacy, such students may be more likely to view their collegiate experience as personally rewarding [11]. Students who frequently experience active learning in their classes may also have more time available for participation in collegiate social communities because they feel that they are able to spend less time on course preparation and studying for examinations. Thus, active learning course practices may directly influence social integration and indirectly affect subsequent institutional commitment and student departure decisions. Tinto [5] presents findings on the role of active learning in influencing student persistence/departure decisions.

The research conducted by Southeastern University and College Coalition for Engineering Education (SUCCEED) provide a unique snapshot of engineering education at a transitional moment in its history [12]. The major component of this study is the design and implementation of a faculty development program. The objectives of this program were: (1) to promote faculty adoption of non-traditional instructional methods and materials that have been proven effective by classroom research studies and (2) to improve institutional support for teaching at each of the eight SUCCEED campuses. The study finds that the percentage of responders giving required team assignments vary from a low of $35 \%$ at one institution to a high of $72 \%$. Assistant professors are more likely than associate or full professors and female professors are more likely than male professors to use in-class group activities and the internet in their teaching, and the assistant professors and female professors are more likely to believe that teaching is devalued in the faculty reward system. In short, there is general agreement that active learning approaches such as PEL have positive outcomes for students but there is great variance in faculty perceptions of nontraditional instructional strategies and the benefit/rewards for increased faculty implementation.

The application of problem-based learning (PBL) to undergraduate engineering education has emerged as an area of research interest over the past few decades, although it does not appear to be the dominant pedagogy for most engineering programs. Educational studies often use lecture as the default style to compare alternative methods to, such as PBL or active learning [13]-[14][15]. An evidencebased comparative study examining the effectiveness of PBL versus lecture-based learning in an introductory engineering course revealed that students retained more knowledge when instructors used a PBL approach [13]. Research in engineering education has shown that building a sense of community and hands-on learning (which is often seen in PBL) contribute to increased student retention and motivation [16]-[17]. In many instances PBL is used as a partial strategy or in addition to traditional curriculum in engineering courses [18]-[19][20][21].

Conventional teaching methods for engineering courses are often lecture-based and emphasize deductive learning in the engineering science courses that students encounter early in their major. Projects are typically a component of engineering design courses, which are usually separate from engineering science and are more likely though not all at the upper level. Problem-based learning and project work share some similarities such as being multi-disciplinary, collaborative, and self-directed, but the two approaches differ slightly in their focus and method of implementation [21]. In problem- 
based learning, students are given a real-life problem to solve as a team and the teacher is seen as a facilitator in the process, rather than a lecturer. The process is self-directed and the students' goal is to refine the problems [22]. Problem-based learning is geared toward acquiring knowledge, whereas project-based learning is directed toward applying knowledge. Project-based learning tends to be more focused on real-world applications and attempts to mimic professional work. Project work tends to take a longer period of time than the tasks in problem-based learning because the projects are more complex and closer to professional reality. Students also tend to produce a concrete product in project work (Table 1).

The suitability of problem-based versus project-based learning for engineering education was compared in [23]. In their review of university engineering programs, they concluded that a mixed-mode approach in which students took more traditionally lecture-based courses covering the fundamentals of engineering combined with project-based components was best for preparing students for the workforce and would be more familiar to instructors than problem-based methods. Perrenet et al. [21] concluded in their review of the literature and in comparing programs that implemented PBL as a partial strategy, that some direct instruction of core concepts is necessary and PBL and project work have some advantageous aspects, such as motivating students as well as being more cognitively engaging than conventional instruction.

The trend of combining or mixing elements of PBL and traditional "topic" focused instruction is also seen with project enhanced learning, as described in [24]. The authors make distinctions between projectenhanced versus project-added implementations. Barroso and Morgan [24] describe project enhanced learning as the implementation of projects in engineering courses that utilize open-ended problems and allow abundant opportunities for students to make decisions in the design and assessment of their work. This is in contrast to a project-added implementation, in which projects are often viewed as an additional lengthy homework assignment and have well-structured problems with clearly defined solutions and outcomes (Table 1).

Krishnan and Nalim [1], offer their own unique approach of project-enhanced learning (PEL), which integrates a major project with a traditional lecture series. In their conceptualization of PEL, core topics are introduced early in a course in relation to a project so that students anticipate what they will learn in lecture. This model is designed for implementation at the early stages of an engineering student's coursework, such as the sophomore year when students take many gateway courses, rather than waiting until content is mastered to begin project work. PEL introduces core concepts early in an engineering program with the integration of a term long project, and the learning is thought to be transferred over time with this method. The current study adopts this interpretation, contrasting PEL with the more student-created project-based learning, but not making it sharply distinct from projectadded implementation. The accommodation of PEL within a traditional lecture-based setting is deliberately intended to ease this intervention into courses where traditional methods are most entrenched. Some benefits of this model have been identified, such as increasing the motivation of students, but more research is needed on PEL. Krishnan and Nalim recommend future studies looking at the longitudinal impact of PEL on student retention in engineering programs, student performance, and students' professional outcomes. 


\section{Section III.}

\section{Research design}

The research project follows a formative case study design to explore the implementation of PEL in gateway engineering courses. The research team has been conducting the evaluation, consisting of process observations, qualitative data collection, and a satisfaction survey. The evaluation results, considered existing data that the research team then used to inform the ongoing design of the proposed research project.

One group of participants in the case study includes instructors who teach gateway engineering courses at Indiana University - Purdue University Indianapolis (IUPUI), University of Illinois Chicago (UIC), and Virginia Commonwealth University (VCU). The participants all agreed to attempt PEL, and some had begun implementation of PEL in their courses. The current study does not include instructors who declined to attempt PEL. The team conducted interviews focused on instructional planning and reflections on PEL as a pedagogical strategy. In addition, instructors were recruited to participate in a series of professional development activities and focus group discussions occurring at various points throughout the ongoing project.

All individual participants were contacted initially by a member of the research team via email or a phone call, and face-to-face during the interview phase. Consent statements were collected for participation in the research and evaluation following all appropriate requirements of Human Subjects Research via Indiana University.

\section{A. Research Team}

The research team, led by Robert Helfenbein, professor in the School of Education at Indiana University - Indianapolis, includes two graduate assistants from the Center for Urban \& Multicultural Education (CUME) involved in literature review, data collection, and preliminary data analysis. The guiding approach for the processes and products of the project follows the Extended-Term Mixed-Method (ETMM) design [2]. This design includes five inter-related principles: (a) developing a long-term time-line, (b) using theory and data to inform decisions, (c) paying attention to formative and summative components of the study, (d) creating sharply focused causal questions regarding impact of the program, and (e) using a variety of quantitative and qualitative evidence to support claims.

\section{B. Research Questions}

1. How are instructors implementing (or not) PEL in their classrooms?

2. How does the implementation of PEL in gateway engineering classrooms follow "best practice" as identified by the research?

3. How supported (by all stakeholders) do instructors feel during the PEL implementation process?

4. What are the challenges to implementing PEL in engineering classrooms?

\section{Methods and Instruments}

\section{Observations}

Using qualitative inquiry and ethnographic methods [25]-[26], team members have conducted a series of observations of PEL instruction, professional development, and coaching. An ethnographic approach is appropriate for building a detailed account of how 
the implementation process unfolds within the context of a classroom and school, and illuminate some of the strengths and challenges of individual instructors as they move through the implementation process.

\section{Focus group discussion}

Team members conducted focus group discussions with the gateway engineering faculty. These were used to check the data collected through the surveys. Sample focus group probes are: "What kinds of support have you been given during the implementation process?"; "How have colleagues helped or hindered your implementation of PEL?" and "How has PEL affected student learning?"

\section{Interviews}

Team members have interviewed faculty members $(n=5)$ about support structures within the School of Engineering \& Technology and about their perceptions of how the implementation process is going overall. Sample interview probes are: "What kinds of support have been provided during the implementation process?"; "How have students responded to PEL?"; and "How has PEL affected student learning?"

\section{Document review}

The research team is collecting lesson and unit plans including entry documents and other PEL-related planning materials, assessment rubrics, samples of student work, and teacher reflections in order to understand $\mathrm{PEL}$ implementation processes and evaluate the objectives. These data were analyzed using content analysis [27].

\section{Survey}

Implementation surveys were disseminated to all participants at the end of the relevant semester. These asked participants a series of questions about their implementation of PEL in their classrooms as well as some of the challenges they have experienced in implementation. Results were compared to the existing data from the PEL evaluation to see how and in what ways teachers have followed through with their plans to implement PEL in their classrooms.

\section{Qualitative Analysis}

The constant-comparative method [28] was employed to allow researchers to use the initial results of one method to extend or clarify the results from another method. As data sets from each of the various sources are obtained, they were initially coded to determine common patterns within the data and develop overarching themes. Throughout subsequent data collection activities, researchers built upon existing data to inform the collection process. Additionally, data previously collected and analyzed was shared with stakeholders including participants for member checking in order to solicit feedback on analyses to date. 


\section{Section IV.}

\section{Findings}

\section{A. How are instructors implementing (or not) PEL in their classrooms?}

Implementation of PEL and other active learning strategies varies among the engineering faculty participating in this study. Differences in approach relate to the educational experiences of the faculty themselves as frequent responses related their teaching approach to the ways in which they experienced engineering education at various points in their career. Typically, the PEL projects followed the model suggested by [1] and included a semester-long supplemental assignment that attempted to provide an authentic application of course concepts.

Faculty report that "best practices" of implementing PEL projects include providing time for project development, advance notice for students to ensure clear expectations, and projects that are designed to be semester long to include a variety of course concepts. One faculty member suggests that it is best to assign the project early in the semester "so that they can get thinking on a concrete example[s]." This additional time allows groups to review the project concept several times as a group and turn to instructors throughout the semester for clarity. Due to the weight and length of the project groups are often strategically composed to provide an intellectual balance in the hopes of peer-to-peer instruction and added camaraderie. However, one instructor commented that his approach to assigning teams varies. Commenting on issues that face PEL he states: "some of the issues of course have to do whenever you have a team project as to how you form the teams and whether a student likes their partner ... I let them choose their own partner, but [I] put some constraints on that because I wanted to make sure that the teams would not [be] very unbalanced in the [intellectual] composition ..."

\section{B. How does the implementation of PEL in gateway engineering classrooms follow "best practice" as identified by research?}

Faculty who attempted PEL perceives significant benefit to implementing PEL in engineering education and cites increased student motivation as the most significant outcome. One participant noted the dual nature of benefit to students "the benefit is that students will have an immediate application of the theory that they are learning-something that is quantifiable [and] something that is physical and that they can relate to." Succinctly put, one faculty member states that PEL provides "an immediate application of the theory that they are learning."

Interestingly, faculty reported that increased contact between instructor and student as an unanticipated positive outcome as an increased number of students attended office hours and engaged faculty outside of class. One subject recalled that time spent processing the project prompted students to "come and discuss the project with me when they're having difficulties [or] when they have questions and I have office hours outside the classroom, but I always make sure that if they [can't] come at that time that I was available to discuss any questions they had on the project." Faculty reported that these interactions expanded beyond the assignment and provided an opportunity for professional mentoring and socialization to the life of an engineer. 
This increased sense of community follows the research that suggests a positive relationship with retention and degree completion efforts.

\section{How supported (by all stakeholders) do instructors feel during the PEL implementation process?}

Faculty report that the support for active learning approaches including PEL is beginning at IUPUI. The time provided through the NSF grant to work together on the generation of projects and sharing of tips and techniques is seen as beneficial for faculty to adopt these practices. It would seem that creating further opportunities for faculty to collaborate would have positive impact on the level of implementation and the possibility of compiling a collection of projects across curricula could be advantageous.

\section{What are the challenges to implementing PEL in engineering classrooms?}

Faculty had strong feelings regarding the barriers to implementing PEL and other active learning strategies in engineering instruction. While it is clear there is an intention on the part of engineering instructors to use PEL to advance the curriculum, there is significant concern that its adoption not be used to the detriment of the content instruction or student growth. PEL, as one instructor states, can be used to fool students into thinking that engineering is "fun" or likened to a science fair that ultimately waters down foundational concepts. Conversely, one participant noted that "the project should not be burdened with a lot of additional busy work that might actually be realistic in terms of what an engineer has to do in a real project, but is not helpful in the learning process," Here the point is made that there needs to be a balance between the authentic tasks of engineers and the larger conceptual goals of the course. Faculty members see the projects as helping students bridge concepts built around mathematical equations to real life applications in the field. It was also suggested that projects can also be used after the course as a way to enhance a student's resume or demonstrate knowledge during job interviews.

Obstacles to implementation can include an instructor's level of comfort with the project's purpose in the course (i.e. they will not have a project just to have a project or for the sake of saying they are practicing PEL) and the time required for faculty to create and assess projects in a research-intensive university. Faculty reported some concern with the level of student comfort or prior experience with PEL or active learning approaches as it is possible that some students prefer a more traditional instructional approach. As some courses are shared enrollment with other subfields in science education (i.e. students from various fields outside of engineering), one instructor reported sacrificing or adjusting a project in order to meet the needs of class as a whole, rather than just a portion.

Although instructors who declined to attempt PEL were not interviewed formally, some reasons given for declining are noted: (a) The class size is too large, and the burden of grading a large number of projects is unacceptable; (b) The effort to create a meaningful project is beyond what a tenure-track instructor can accomplish, given pressing research goals; and (c) The best way for students to learn difficulty engineering science fundamentals is to work hard on more 
homework problems. There also appear to be interesting differences between the concerns of experienced, perhaps more conservative, instructors, and younger, novice faculty members. We may generalize from these observations that an incremental approach to introduce PEL that also anticipates these perceived barriers may in the long-term lead to more successful transformation of the student's learning success in gateway courses in the engineering curriculum.

\section{Section V.}

\section{Concluding Thoughts}

An on-going study of faculty perceptions of project-enhanced learning in early engineering education is reported in this paper. There are well-researched and demonstrated benefits of active learning strategies in engineering education, including the use of projects. PEL is a carefully calibrated approach to active learning using projects that seeks to retain and enhance traditional lecture-based instruction.

Instructors who agreed to attempt PEL expressed satisfaction with student learning outcomes, despite reservations about workload and potential dilution of academic rigor. They were particularly impressed with increased student motivation and with the immediacy of application provided by the project, as well as the socialization of students into the community and culture of engineering. They also noted the increased interaction of students with each other and with instructors.

Instructors expressed concern about misleading students about the challenges and rigor of engineering education by focusing on the project perhaps at the expense of more analytical tasks essential to the course topics. They achieved a balance between project benefits and course goals by designing project tasks to closely align with specific learning outcomes of the course, and whittling down less relevant activity.

Support from an NSF grant allowed instructors some time for creation of projects and preparation for teaching. For some instructors, PEL materials were already available and had been used in their course previously. Using ETMM to study PEL perceptions, utilizing multiple scholarly sources and research approaches over a long-term time-line, allowed the research team to delve deeply into multiple facets of PEL. Insight provided in this research embarks on a discovery on not only how pedagogical practices in engineering influences student learning, but how administering it impacts the professoriate. This study does not investigate whether instructors would attempt PEL without such assistance. This study has also not examined the thinking of instructors who either ignored the PEL activity or specifically declined to attempt PEL. These questions would be fruitful areas for future research.

This paper points to several conclusions about PEL and faculty implementation. As an active learning approach, PEL provides increased opportunity for faculty/student interaction and enhances traditional lecture-based instruction with authentic application of engineering concepts. Faculty report positive increases in student motivation, socialization to the field, and learning outcomes as a result of implementation. Faculty satisfaction was a direct result from intentional project design that incorporated specific learning outcomes within courses and minimized "busy work." While the need for more research is clear, this project suggests that the positive impacts of PEL may go well beyond course 
enrollment numbers by increasing engineering faculty and student satisfaction and broadening instruction experiences in engaging ways. 


\section{Tables}

Table 1. Focus and Components of Selected Teaching Methods [24]

\begin{tabular}{|c|c|c|c|}
\hline $\begin{array}{l}\text { Problem-based learning } \\
\text { (PBL) }\end{array}$ & Project-based learning & $\begin{array}{l}\text { Project-enhanced } \\
\text { learning (PEL) }\end{array}$ & $\begin{array}{l}\text { Project added } \\
\text { implementation }\end{array}$ \\
\hline $\begin{array}{l}\text { - Acquisition of } \\
\text { knowledge } \\
\text { - Students solve } \\
\text { real-life problems } \\
\text { as a team } \\
\text { - Teacher is seen as } \\
\text { a facilitator in the } \\
\text { process } \\
\text { - Students' goal is } \\
\text { to refine the } \\
\text { problems }\end{array}$ & 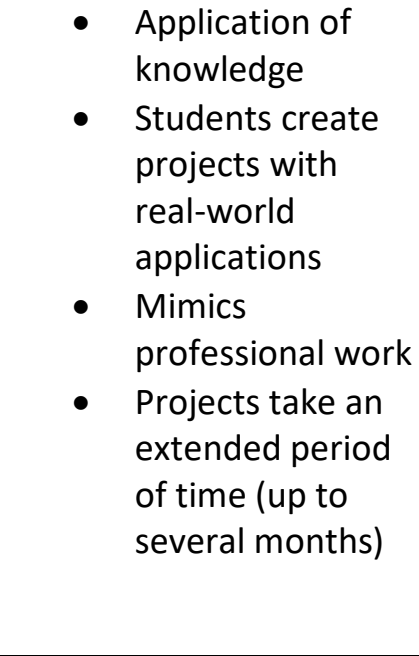 & $\begin{array}{l}\text { - A project is } \\
\text { integrated with a } \\
\text { traditional } \\
\text { lecture-based } \\
\text { course } \\
\text { - Can be } \\
\text { implemented in a } \\
\text { gradual and } \\
\text { transferable way } \\
\text { over time and } \\
\text { among multiple } \\
\text { sections and } \\
\text { instructors }\end{array}$ & $\begin{array}{l}\text { Projects are an } \\
\text { added course } \\
\text { component that } \\
\text { can be seen as a } \\
\text { larger and more } \\
\text { complex } \\
\text { homework } \\
\text { problem } \\
\text { Well-structured } \\
\text { problems with } \\
\text { clear instructions } \\
\text { for completion } \\
\text { Well-defined } \\
\text { project outcome }\end{array}$ \\
\hline
\end{tabular}




\section{Authors}

Robert J. Helfenbein

Center for Urban \& Multicultural Education (CUME), School of Education, Indiana University Purdue University Indianapolis, Indianapolis, USA.

M. Razi Nalim

School of Engineering \& Technology, Indiana University - Purdue University Indianapolis, Indianapolis, USA.

Manikanada K. Rajagopal

School of Engineering \& Technology, Indiana University - Purdue University Indianapolis, Indianapolis, USA. 


\section{References}

1. S. Krishnan and M. R. Nalim, "Project based Learning in Introductory Thermodynamics," Proceedings of the 116th American Society of Engineering Education Annual Conference, Austin, TX. Paper AC 2009-1911, 2009.

2. M. Chatterji, "Evidence on "what works": An argument for extended term mixed method (ETMM) evaluation designs". Educational Researcher, vol. 33:9, pp. 3-13, 2004.

3. B. Glasser, "The constant comparative method of qualitative analysis," Social Problems, vol. 12:4, pp. 436-445, 1965.

4. R. Nalim, L. Li, P. Orono, R. Helfenbein, W. Yu, M. Mital, "Project- Enhanced Learning in Challenging Engineering Science Courses," ASEE Illinois/Indiana 2012 Section Conference, 2012.

5. V. Tinto, "Leaving college: Rethinking the causes and cures of student attrition," Chicago: The University of Chicago Press, 1993.

6. J. M. Braxton, J. F. Milem, A. S. Sullivan, "The Influence of Active Learning on the College Student Departure Process," The Journal of Higher Education, vol. 71: 5, pp. 569-590, 2000.

7. J. A. Anderson, and M. Adams, "Acknowledging the learning styles of diverse student populations: Implications for instructional design". In L. L. B. Border and N. Van Note Chism (Eds.), Teaching for diversity. No. 49: New directions for teaching and learning, pp. 19-33, San Francisco: Jossey-Bass, 1992.

8. A. W. Chickering, and Z. F.Gamson, "Seven Principles for Good Practice in Undergraduate Education," AAHE Bulletin, pp. 3-7, 1987.

9. D. W. Johnson, R. T. Johnson, and K. A. Smith, "Cooperative Learning: Increasing College Faculty Instructional Productivity," ASHE-FRIC Higher Education Report No. 4. Washington, D.C.: School of Education and Human Development, George Washington University, 1991.

10. W. McKeachie, P. Pintrich, L. Yi-Guang, and D. Smith, "Teaching and Learning in the College Classroom: A Review of the Research Literature", Ann Arbor: Regents of the University of Michigan, 1986.

11. J. F. Milem, J. B. Berger, "A modified model of college student persistence: Exploring the relationship between Astin's theory of involvement and Tinto's theory of student departure". Journal of College Student Development, vol. 38, pp. 387-400, 1997.

12. R. M. Felder, R. Brent, T. K. Miller, C. E. Brawner, R. H. Allen, "Faculty Teaching Practices and Perceptions of Institutional Attitudes Toward Teaching at Eight Engineering Schools," ASEE FIE Conference, Session T1G, 101-105, 1998.

13. C. Hsieh, and L. Knight, "Problem-based learning for engineering students: An evidencebased comparative study". The Journal of Academic Librarianship, vol. 34: 1, pp. 25-30, 2008.

14. P. T. Terenzini, A. F. Cabrera, C. L. Colbeck, J. M. Parente, and S. A. Bjorklund," Collaborative learning vs. lecture/discussion: Students' reported learning gains. Journal of Engineering Education, vol. 90: 1, pp. 123-130, 2001.

15. J. Dutton, M. Dutton, and J. Perry, "Do online students perform as well as lecture students?," Journal of Engineering Education, pp. 131-136, 2001. 
16. S. D. Sheppard, K. Macatangay, A. Colby, and W. M. Sullivan. "Educating Engineers: Designing for the Future of the Field," The Carnegie Foundation for the Advancement of Teaching Series, Jossey-Boss Publications, San Francisco, CA, 2008.

17. J. Meyer, N. Lamm, and J. Smith, "Retaining freshman engineering students through participation in a first-year learning community: What works and what doesn't.," American Society for Engineering Education. 2007.

18. P. Cawley, A problem-based module in mechanical engineering In D. Boud and G. Feletti (Eds.), The Challenge of Problem Based Learning London: Kogan Page. pp. 177-185, 1991.

19. I. Denayer, K.Thaels, J. V. Sloten, and R. Gobin," Teaching a structured approach to the design process for undergraduate engineering students by problem-based education," European Journal of Engineering Education, vol. 28: 2, pp. 203-214, 2003.

20. D. R. Woods, "Problem-based learning for large classes in chemical engineering. In L. A. Wilkerson and W. H. Gijselaers (Eds.), Bringing Problem-based Learning to Higher Education: Theory and Practice, pp. 91-99. San Francisco, CA: Jossey-Bass, 1996.

21. J. C. Perrenet, P. A. J. Bouhuijs, and J. G. M. M. Smits, "The Suitability of Problem-based Learning for Engineering Education: theory and practice," Teaching in Higher Education, vol. 3:5, pp. 345-358, 2000.

22. L.F. Johnson, R. S. Smith, J.T. Smythe, and R. K. Varon, Challenge-Based Learning: An Approach for Our Time. Austin, Texas: The New Media Consortium, 2009.

23. J. E. Mills, and D. F. Treagust, "Engineering education-Is problem-based or project-based learning the answer?," Australasian Journal of Engineering Education, pp. 1-16, 2003.

24. L. R. Barroso, and J. R. Morgan, "Project enhanced learning: Addressing ABET outcomes and linking the curriculum," Journal of Professional Issues in Engineering Education and Practice, vol. 135: 1, pp. 11-20, 2009.

25. J. W. Creswell ,"Qualitative inquiry and research design: Choosing among five approaches," Thousand Oaks, CA, 2007.

26. P. F. Carspecken, "Critical ethnography in educational research: $A$ theoretical and practical guide". New York and London: Routledge. 1996

27. K. A. Neuendorf, "The content analysis guidebook," Thousand Oaks, CA: Sage Publications, 2002.

28. B. G. Glaser, and A. L. Strauss, "The discovery of grounded theory: Strategies for qualitative research," Chicago: Aldine Publishing Company, 1967. 